\title{
Curcumin enhances the antitumor effect of ABT-737 via activation of the ROS-ASK1-JNK pathway in hepatocellular carcinoma cells
}

\author{
RUINIAN ZHENG ${ }^{1,2}$, ZHIJIAN YOU ${ }^{2}$, JUN JIA $^{2}$, SHUNHUAN LIN $^{2}$, SHUAI HAN $^{3}$, \\ AIXUE LIU ${ }^{4}$, HUIDONG LONG ${ }^{5}$ and SENMING WANG ${ }^{1}$ \\ ${ }^{1}$ Department of Oncology, Zhujiang Hospital, Southern Medical University, Guangzhou, Guangdong 510282; \\ ${ }^{2}$ Department of Oncology, Dongguan People's Hospital, Dongguan, Guangdong 523000; \\ ${ }^{3}$ Department of General Surgery, Zhujiang Hospital, Southern Medical University, Guangzhou, Guangdong 510282; \\ ${ }^{4}$ Department of Oncology, The Second People's Hospital of Shenzhen, Shenzhen, Guangdong 518035; \\ ${ }^{5}$ Department of Internal Medicine, Affiliated Cancer Hospital of Guangzhou Medical University, \\ Guangzhou, Guangdong 510095, P.R. China
}

Received January 7, 2015; Accepted October 14, 2015

DOI: $10.3892 / \mathrm{mmr} .2015 .4715$

\begin{abstract}
At present, the therapeutic treatment strategies for patients with hepatocellular carcinoma (HCC) remain unsatisfactory, and novel methods are urgently required to treat this disease. Members of the B cell lymphoma (Bcl)-2 family are anti-apoptotic proteins, which are commonly expressed at high levels in certain HCC tissues and positively correlate with the treatment resistance of patients with HCC. ABT-737, an inhibitor of Bcl-2 anti-apoptotic proteins, has been demonstrated to exhibit potent antitumor effects in several types of tumor, including HCC. However, treatment with ABT-737 alone also activates certain pro-survival signaling pathways, which attenuate the antitumor validity of ABT-737. Curcumin, which is obtained from Curcuma longa, is also an antitumor potentiator in multiple types of cancer. In the present study, the synergistic effect of curcumin and ABT-737 on HCC cells was investigated for the first time, to the best of our knowledge. It was found that curcumin markedly enhanced the antitumor effects of ABT-737 on HepG2 cells, which was partially dependent on the induction of apoptosis, according to western blot analysis and flow cytometric apoptosis analysis. In addition, the sustained activation of the ROS-ASK1-c-Jun N-terminal kinase pathway may be an important mediator of the synergistic effect of curcumin and ABT-737. Collectively, these results indicated that the combination of curcumin and
\end{abstract}

Correspondence to: Dr Senming Wang, Department of Oncology, Zhujiang Hospital, Southern Medical University, 253 Middle Industrial Avenue, Guangzhou, Guangdong 510282, P.R. China

E-mail: senmingwang137@yeah.net

Key words: curcumin, ABT-737, reactive oxygen species, c-Jun $\mathrm{N}$-terminal kinase
ABT-737 can efficaciously induce the death of HCC cells, and may offer a potential treatment strategy for patients with HCC.

\section{Introduction}

Hepatocellular carcinoma (HCC) is a common type of cancer worldwide, and is the third most common cause of cancer-associated mortality (1). The therapeutic effects of current treatment strategies for patients with $\mathrm{HCC}$ remain unsatisfactory, thus it is important to develop novel methods of treatment for this disease $(2,3)$.

B cell lymphoma (Bcl)-2, Bcl-extra large (xL) and Bcl-2-like-2 (w) are the anti-apoptotic protein members of the Bcl-2 family in mammalian cells, which contain four $\mathrm{BH}$ domains (BH1, BH2, BH3 and BH4) (4). The Bcl-2 anti-apoptotic proteins have been reported to prevent mitochondrial outer membrane permeabilization and repress apoptosis under stress (5). The expression of Bcl-2 anti-apoptotic proteins is often increased in numerous types of tumor tissue, which is commonly associated with treatment resistance $(5,6)$. Previous studies have found that the levels of $\mathrm{Bcl}-2$ anti-apoptotic proteins are closely associated with the pathological grade and survival rate of patients with HCC (7-9). Therefore, the targeting of Bcl-2 anti-apoptotic proteins may be a candidate for the treatment of patients with HCC. ABT-737 is an inhibitor of Bcl-2, Bcl-xL and Bcl-w, which is currently in phase I clinical trials for patients with leukemia (10-12). It has been previously reported that ABT-737 also has antitumor effects in HCC cell lines (13-17). However, certain pro-survival signaling pathways in HCC cells are often activated upon ABT-737 treatment, which attenuates the antitumor effect of ABT-737 $(13,16,17)$. Therefore, novel treatment strategies require investigation in order to improve the efficacy of ABT-737.

Curcumin, also known as diferuloylmethane, is obtained from Curcuma longa, and is regarded as a potent anticancer drug in various types of tumor, including HCC (18-21). Previous studies have demonstrated that curcumin is able to 
effectively inhibit the proliferation of HCC cells in vitro and in vivo (22-25). In addition, curcumin significantly enhances the antitumor effects of certain traditional chemotherapeutic drugs and molecular-targeted drugs (26-32). However, the synergistic effect of curcumin and ABT-737 remains to be fully elucidated.

The present study aimed to investigate the antitumor effects of combination therapy of ABT-737 with curcumin on HepG2 cells. Whether curcumin enhances the antitumor effect of ABT-737 via the induction of apoptosis in HepG2 cells was investigated, and the potential involvement of the reactive oxygen species (ROS)-apoptosis signal-regulating kinase 1 (ASK1)-c-Jun N-terminal kinase (JNK) pathway was examined.

\section{Materials and methods}

Reagents. HyClone Dulbecco's modified Eagle's medium (DMEM) nutrient mixture and HyClone fetal bovine serum (FBS) were purchased from Thermo Fisher Scientific, Inc. (Waltham, MA, USA). ABT-737, SP600125 and $N$-acetyl-L-cysteine (NAC) were purchased from Sigma-Aldrich (St. Louis, MO, USA). An Annexin V-Fluorescein Isothiocyanate (FITC)/Propidium Iodide (PI) Apoptosis Detection kit was purchased from Beyotime Institute of Biotechnology (Beijing, China). Cell Counting Kit-8 (CCK-8) reagent was obtained from Dojindo Molecular Technologies, Inc. (Kumamoto, Japan). Invitrogen Lipofectamine 2000 was obtained from Thermo Fisher Scientific, Inc. Curcumin was purchased from Sigma-Aldrich and dissolved in dimethylsulfoxide (Sigma-Aldrich) to prepare a stock solution, which was used for treating HepG2 cells. Antibodies against Bcl-2 (cat. no. sc-25780), poly(ADP ribose) polymerase 1 (PARP-1; cat. no. sc-25780) and caspase-3 (cat. no. sc-7148) were purchased from Santa Cruz Biotechnology, Inc. (Dallas, TX, USA). Rabbit polyclonal antibodies against myeloid cell leukemia-1 (Mcl-1; cat. no. 4572), total-JNK (cat. no. 9252) and phosphorylated (p-)JNK (cat. no. 9255), and against glyceraldehyde 3-phosphate dehydrogenase (GAPDH; cat. no. 2118) were purchased from Cell Signaling Technology, Inc. (Danvers, MA, USA). Horseradish peroxidase-conjugated goat anti-rabbit (cat. no. A0208) and anti-mouse IgG (cat. no. A0216) antibodies were purchased from Beyotime Institute of Biotechnology.

Cell culture. The HepG2 human HCC cell line was obtained from the American Type Culture Collection (Manassas, VA, USA) and cultured in DMEM supplemented with 10\% FBS, streptomycin $(100 \mu \mathrm{g} / \mathrm{ml})$ and penicillin $(100 \mathrm{U} / \mathrm{ml})$ (both from Sigma-Aldrich) at $37^{\circ} \mathrm{C}$ in a humidified atmosphere containing $5 \% \mathrm{CO}_{2}$. All seeded cells were grown to $70-80 \%$ confluence prior to treatment. Cells were treated with $2 \mu \mathrm{M}$ curcumin, $10 \mu \mathrm{M}$ ABT-737 or $10 \mathrm{mM}$ NAC for $24 \mathrm{~h}$ and then subjected to further experiments.

Hoechst 33258 staining. The treated cells were fixed with $4 \%$ paraformaldehyde (Sigma-Aldrich) for $10 \mathrm{~min}$ at room temperature and then washed with phosphate-buffered saline (PBS) three times. Subsequently, the cells were incubated with Hoechst 33258 (Sigma-Aldrich) according to the manufacturer's instructions. The cells were then observed under a fluorescence microscope (IX81; Olympus Corp., Tokyo, Japan) to identify apoptotic cells.

Trypan blue exclusion assay. Cells were treated with ABT-737 $(0,1,5$ or $10 \mu \mathrm{M})$ and/or curcumin $(0$ or $2 \mu \mathrm{M})$ for $36 \mathrm{~h}$, harvested and suspended in PBS. The cells were then added with an equal volume of $0.08 \%$ Trypan blue solution (Sigma-Aldrich), and were incubated for $5 \mathrm{~min}$ at room temperature. Subsequently, the living and dead cells were counted using an optical microscope. The cells failing to exclude the blue dye were defined as dead cells, and the cell death rate was estimated as the percentage of dead cells.

Cytotoxicity assay. The cytotoxicity assay was performed using CCK-8 reagent. In brief, the HepG2 cells were seeded into 96-well plates at a density of $1 \times 10^{3}$ cells/well. After $24 \mathrm{~h}$, the cells were incubated with ABT-737 $(0,1,5$ or $10 \mu \mathrm{M})$ and/or curcumin $(0$ or $2 \mu \mathrm{M})$ for $36 \mathrm{~h}$. Subsequently, CCK-8 reagent was added to each well, according to the manufacturer's protocol. Following incubation in the dark for $50 \mathrm{~min}$ at room temperature, the absorption values of the cells were detected at a wavelength of $450 \mathrm{~nm}$ using a Multiskan Spectrum microplate reader (Thermo Fisher Scientific, Inc.).

Western blot analysis. The total proteins of the treated cells were extracted from the whole-cell protein lysates prepared with radioimmunoprecipitation assay lysis and extraction buffer (Thermo Fisher Scientific) according to manufacturer's instruction at room temperature with centrifugation at $17,320 \mathrm{x}$ g for $5 \mathrm{~min}$ at $4^{\circ} \mathrm{C}$, and the concentration of the protein was measured using a Bicinchoninic Acid (BCA) Protein Assay kit (Sigma-Aldrich). Subsequently, $60 \mu \mathrm{g}$ protein of each sample was loaded for $10 \%$ polyacrylamide gel electrophoresis and then transferred onto polyvinylidene difluoride (PVDF) membranes (Thermo Fisher Scientific). The PVDF membranes were then incubated with 5\% albumin in PBS with 1\% Tween-20 (TBST) for $2 \mathrm{~h}$ at $37^{\circ} \mathrm{C}$. Subsequently, the membranes were separately incubated with antibodies against Bcl-2 (1:1,000), Mcl-1 (1:2,000), PARP $(1: 1,000)$, cleaved caspase-3 (1:500), total-JNK $(1: 1,000)$, phosphorylated (p)-JNK (1:200) and GAPDH $(1: 3,000)$ for $12 \mathrm{~h}$ at $4^{\circ} \mathrm{C}$. Following incubation and washing with PBST three times, the membranes were separately incubated with goat anti-rabbit and anti-mouse $\mathrm{IgG}$ for $1 \mathrm{~h}$ at $37^{\circ} \mathrm{C}$. Immunoreactivity was then visualized by adding chemiluminescent peroxidase substrate (Thermo Fisher Scientific) in the dark. The chemiluminescence signal was recorded using the ChemiDoc XRS imaging system (Bio-Rad Laboratories, Hercules, CA, USA). Data analysis and quantification were performed using Quantity One software (version 4.6; Bio-Rad Laboratories, Inc.)

ROS detection. The HepG2 cells were seeded into 12-well plates and were cultured overnight, following which the cells were treated with the different treatments. Following treatment, the cells were washed with PBS three times, and the 2',7'-dichlorofluorescin diacetate fluorescent probe (Sigma-Aldrich) was added, according to the manufacturer's protocol. Subsequently, the cells were washed and harvested in PBS. The fluorescent value of each sample was then detected at a $488 \mathrm{~nm}$ excitation wavelength and a $525 \mathrm{~nm}$ emission wavelength using a fluorescent plate reader $\left(\right.$ VICTOR $^{\mathrm{TM}} \mathrm{X} 5$ 
A

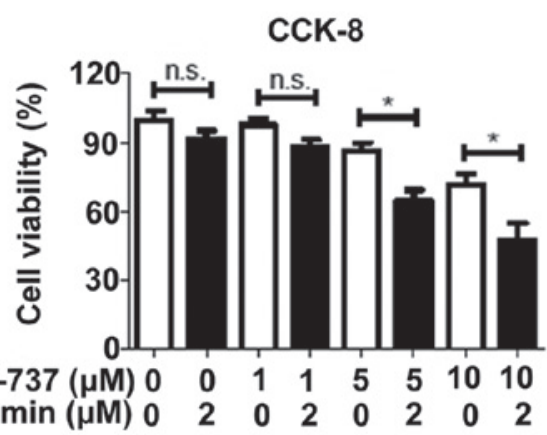

B

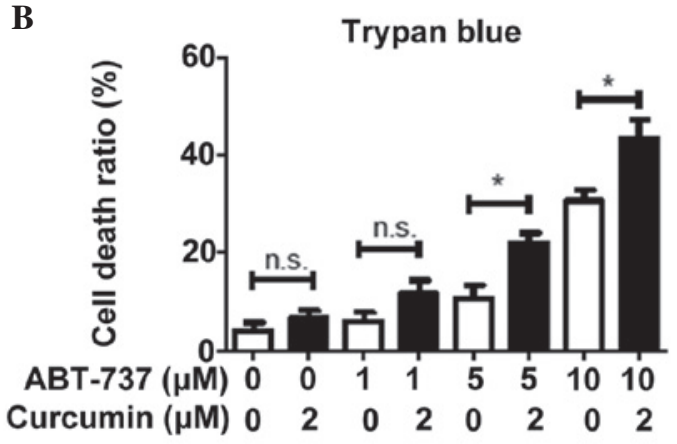

C
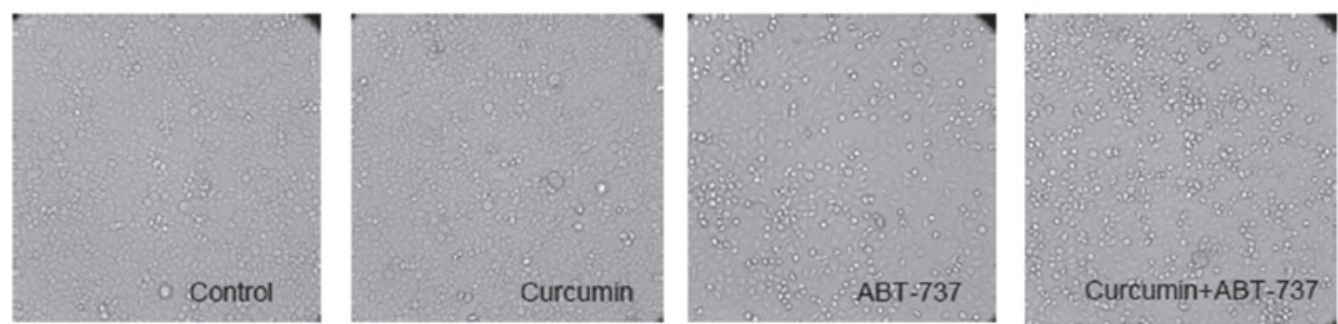

Figure 1. Curcumin enhances the antitumor effects of ABT-737 on HepG2 hepatocellular carcinoma cells. (A) HepG2 cells were seeded into 96 -well plates and cultured overnight. The cells were then treated with curcumin and ABT-737 at the indicated concentrations for $36 \mathrm{~h}$. Subsequent to treatment, a CCK-8 assay was used to determine the cell viability. (B) HepG2 cells were treated as in A, following which a Trypan blue exclusion assay was used to measure the total cell death ratio, according to the following equation: Cell death ratio $=$ number of dead cells / (number of living cells+number of dead cells) $\mathrm{x} 100 \%$. ${ }^{*} \mathrm{P}<0.05$. (C) HepG2 cells were seeded in 6-well plates and cultured overnight. The cells were then separately treated with $1 \%$ dimethyl sulfoxide, $2 \mu \mathrm{M}$ curcumin, $10 \mu \mathrm{M}$ ABT-737 and $2 \mu \mathrm{M}$ curcumin $+10 \mu \mathrm{M}$ ABT-737 for $36 \mathrm{~h}$. Subsequently, the cells were observed under a microscope (magnification, $\mathrm{x} 100$ ) and floating cells were regarded as dead cells. The combination of ABT-737 and curcumin resulted in an increased number of floating cells and therefore cell death compared with single treatments or the control group. CCK-8, Cell Counting Kit-8; n.s., not significant.

Multilabel Plate Reader; Perkin Elmer, Waltham, MA, USA), with the ROS levels presented as the fold induction.

Transfection with small interfering RNA (siRNA). siRNA for ASK1 (5'-AAUUGCAGUCUGCACAGCCUUUCGG-3') or control siRNA were purchased from Shanghai GenePharma Co., Ltd. (Shanghai, China). The HepG2 cells were seeded into six-well plates and were cultured overnight. The cells at $70 \%$ confluence were then transfected with siRNA (100 pmol/well) using Lipofectamine 2000, according to the manufacturer's protocol.

Annexin V-FITC/PI staining. The treated cells, including the adherent and floating cells were harvested in PBS. The cells were then incubated with annexin V-FITC and PI for 15 min at room temperature. The stained cells were then analyzed using flow cytometry (FACSCalibur; BD Biosciences, San Jose, CA, USA).

Caspase-3 activity detection. Caspase- 3 activity was detected by the specific caspase-3 substrate, Ac-DEVD-AM C (Sigma-Aldrich). Briefly, the treated cells were suspended in radioimmunoprecipitation assay cell lysis buffer. The proteins were extracted according to the abovementioned procedure and the concentration was measured using the BCA kit. Subsequently, Ac-DEVD-AM C was added to each cell lysate containing $200 \mu \mathrm{g}$ protein, according to the manufacturer's protocol. Following incubation at $37^{\circ} \mathrm{C}$ for $1 \mathrm{~h}$, the caspase-3 activity was measured by the fluorescence intensity at an excitation wavelength at $365 \mathrm{~nm}$ and an emission wavelength at
$435 \mathrm{~nm}$ using a Victor ${ }^{\mathrm{TM}}$ X5 Multilabel Plate Reader (Perkin Elmer, Waltham, MA, USA).

Statistical analysis. All experiments in the present study were performed a minimum of three times. The data are expressed as the mean \pm standard deviation. Statistical differences were analyzed using two-way analysis of variance. Excel 2010 (Microsoft Corp., Redmond, WA, USA) software was used for all statistical analyses. $\mathrm{P}<0.05$ was considered to indicate a statistically significant difference.

\section{Results}

Curcumin enhances the antitumor effect of ABT-737 on HepG2 HCC cells. In the present study, a cytotoxicity assay was used to evaluate the synergistic effect of curcumin and ABT-737 on HepG2 cells. As shown in Fig. 1A, no significant alterations in cell viability were observed when the cells were treated with $2 \mu \mathrm{M}$ curcumin alone for $24 \mathrm{~h}$, whereas cell viability was observed to reduce in a dose-dependent manner following co-treatment with ABT-737. In addition, $2 \mu \mathrm{M}$ curcumin was observed to significantly enhance the cytotoxic effects of ABT-737 (5 and $10 \mu \mathrm{M}$ ) on HepG2 cells (Fig. 1A). To determine whether the cytotoxic effects of ABT-737 and curcumin were associated with the increase in the number of dead cells, a Trypan blue exclusion assay was used to calculate the rate of cell death. As shown in Fig. 1B, 5 or $10 \mu \mathrm{M}$ ABT-737-induced cell death was significantly increased by the addition of $2 \mu \mathrm{M}$ curcumin, which indicated that the increase in cell death may be due to the 

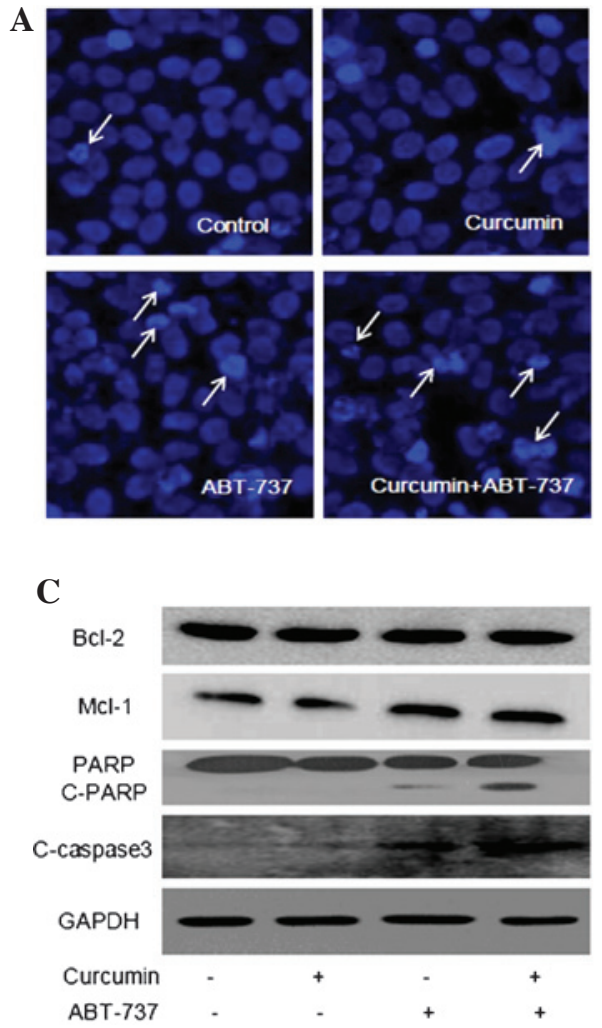

B
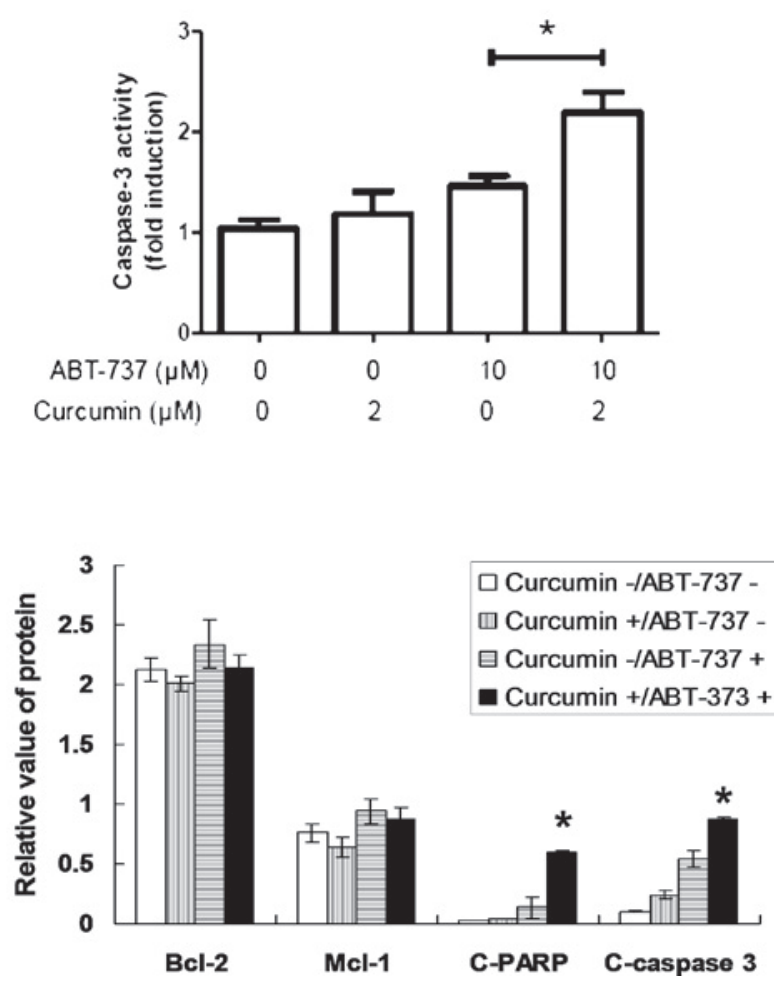

Figure 2. ABT-737 combined with curcumin significantly induces apoptosis in HepG2 cells. (A) HepG2 cells were separately treated with $1 \%$ dimethyl sulfoxide, $2 \mu \mathrm{M}$ curcumin, $10 \mu \mathrm{M}$ ABT-737 and $2 \mu \mathrm{M}$ curcumin $+10 \mu \mathrm{M}$ ABT-737 for $24 \mathrm{~h}$, and were stained with Hoechst 33258 . Subsequently, the morphological characteristics of the nuclei were observed under a fluorescence microscope (magnification, x630). The white arrows represent abnormal nuclei with typical characteristics of apoptosis. (B) HepG2 cells were treated as in A, following which caspase activity was detected and presented as fold induction. (C) HepG2 cells were treated as in (A), following which the total cellular proteins were extracted. Subsequently, the proteins were loaded for western blotting and the levels of Bcl-2, Mcl-1, PARP/C-PARP and C-caspase-3 were assessed. Data are expressed as the mean \pm standard deviation. "P<0.05 as indicated or vs. all other groups. Bcl-2, B cell lymphoma-2; Mcl-1, myeloid cell leukemia-1; PARP, poly adenosine diphosphate-ribose polymerase; C-, cleaved; GAPDH, glyceraldehyde 3-phosphate dehydrogenase.

synergistic effect of curcumin and ABT-737 on HepG2 cells. Additionally, the number of floating cells, defined as dead cells, in the DMEM of each well were markedly increased in the curcumin and ABT-737 co-treatment group when visually observed under a light microscope (Fig. 1C). These results further confirmed the synergistic effect of curcumin and ABT-737 on HepG2 cells.

ABT-737 combined with curcumin significantly induces apoptosis in HepG2 cells. As apoptosis is a key part of ABT-737-mediated cell death $(16,33,34)$, whether curcumin promotes ABT-737-induced apoptosis in HepG2 cells was further investigated in the present study. Hoechst 33258 staining demonstrated that the number of abnormal nuclei with the typical characteristics of apoptosis was significantly increased in the HepG2 cells co-treated with curcumin and ABT-737, compared with the cells treated with ABT-737 alone (Fig. 2A). In addition, the activity of caspase-3, which is a key executor of typical apoptotic pathway, was markedly increased (Fig. 2B), and the level of cleaved caspase-3 also increased accordingly (Fig. 2C). These data suggested that curcumin and ABT-737 synergistically induce apoptosis of HepG2 cells.

ROS levels are increased in HepG2 cells following co-treatment with ABT-737 and curcumin. A previous study demonstrated that ROS are important in ABT-737-induced apoptosis (16), therefore, the present study further investigated the role of ROS on the induction of apoptosis in HepG2 cells with the co-treatment of curcumin and ABT-737. As shown in Fig. 3A, co-treatment with curcumin and ABT-737 significantly increased the level of ROS in HepG2 cells. In addition, the administration of the antioxidant NAC attenuated the synergistic effect of curcumin and ABT-737 on the induction of apoptosis (Fig. 3B-D), which indicated that the increase of ROS was an important factor for the antitumor effect of curcumin and ABT-737.

Increased ROS levels promote the sustained activation of $J N K$, which leads to apoptosis in HepG2 cells. As increased levels of ROS have been reported to activate JNK $(35,36)$, and sustained activation of JNK has been demonstrated as a mechanism for ABT-737-induced apoptosis (16), changes in the activity of JNK in curcumin and ABT-737 co-treated cells were further examined in the present study. As shown in Fig. 4A, JNK was not activated at the $18 \mathrm{~h}$ time point in the curcumin $(2 \mu \mathrm{M})$-treated cells or ABT-737 $(10 \mu \mathrm{M})$-treated cells, however, JNK was activated in the curcumin and ABT-737 co-treated cells. In addition, the JNK inhibitor, SP600125, significantly suppressed the apoptosis, which was induced by the combination of curcumin and ABT-737 in the HepG2 cells (Fig. 4B). These results indicated that 
A
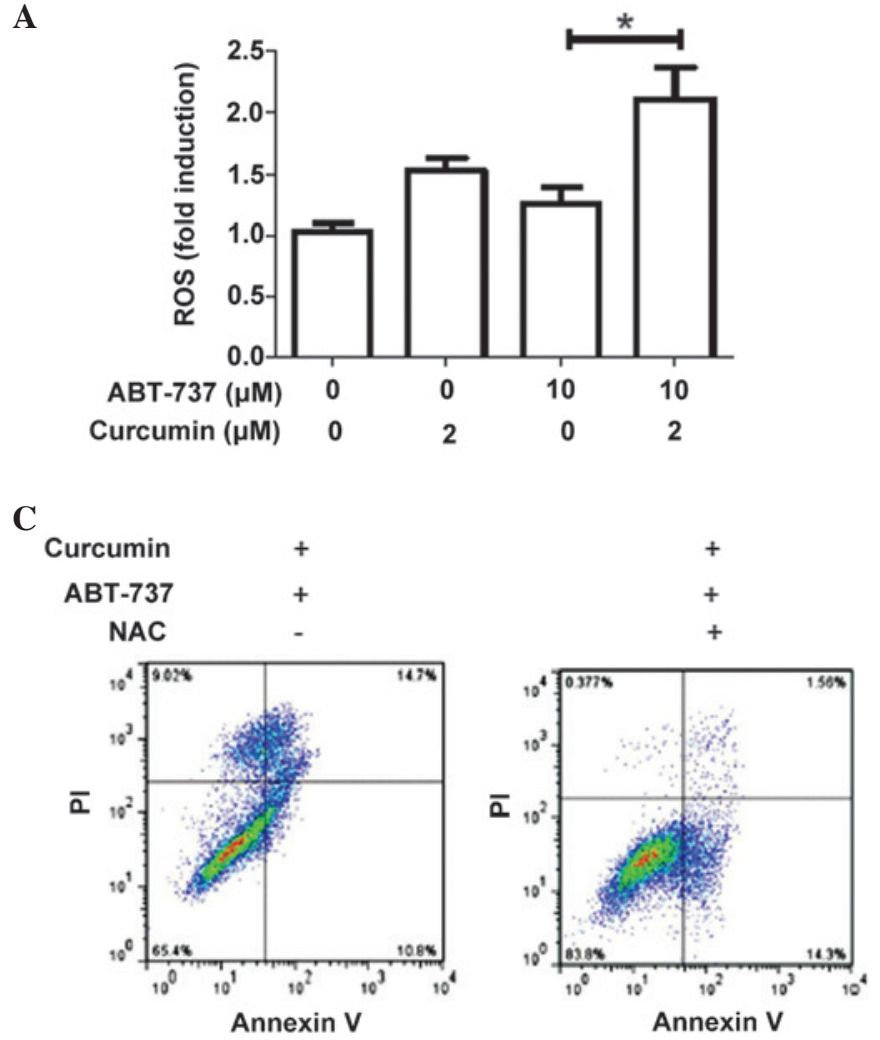

B
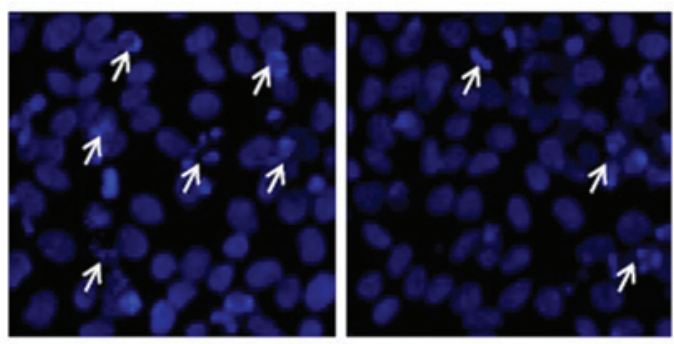

Curcumin

ABT-737

NAC

D

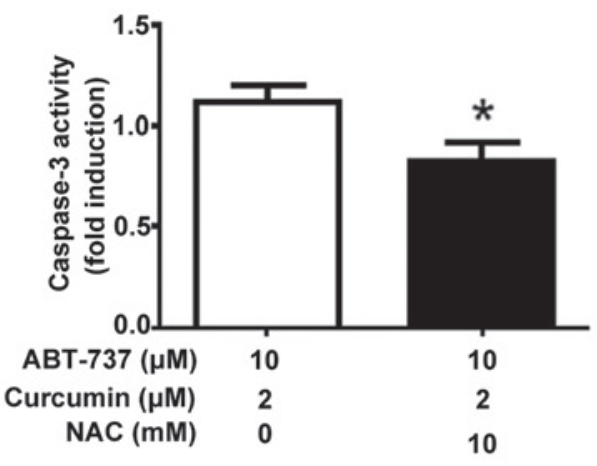

Figure 3. ROS levels are increased in HepG2 cells following co-treatment with ABT-737 and curcumin. (A) HepG2 cells were separately treated with $1 \%$ dimethyl sulfoxide, $2 \mu \mathrm{M}$ curcumin, $10 \mu \mathrm{M}$ ABT-737 and $2 \mu \mathrm{M}$ curcumin $+10 \mu \mathrm{M}$ ABT-737 for $24 \mathrm{~h}$, following which a 2',7'-dichlorofluorescin diacetate probe was used to measure the levels of cellular ROS. HepG2 cells were treated with $2 \mu \mathrm{M}$ curcumin and $10 \mu \mathrm{M}$ ABT-737 for $24 \mathrm{~h}$ in the presence or absence of the antioxidant, NAC (10 mM). Subsequently, the levels of HepG2 cell apoptosis were analyzed using (B) Hoechst 33258 staining (white arrows indicate cells undergoing apoptosis with nuclear fragmentation visualized by Hoechst staining), (C) Annexin V-fluorescein isothiocyanate/PI staining and (D) caspase-3 activity detection. Data are expressed as the mean \pm standard deviation. "P<0.05. ROS, reactive oxygen species; PI, propidium iodide; NAC, N-acetyl-L-cysteine.

A

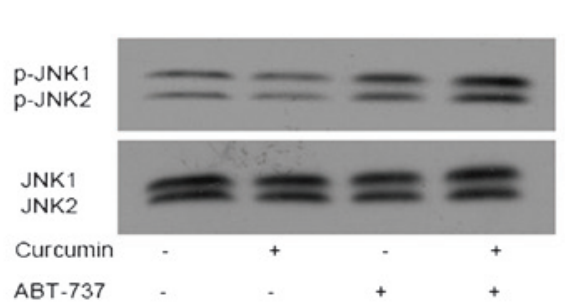

\section{B}

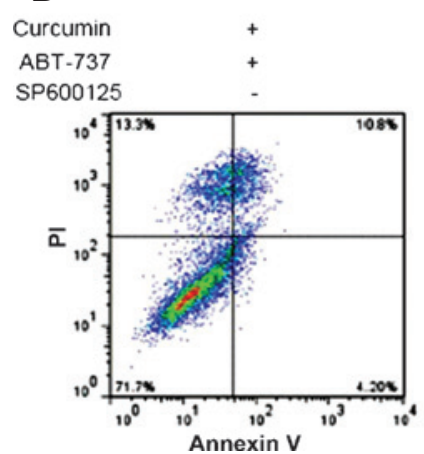

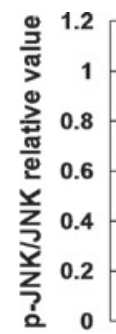

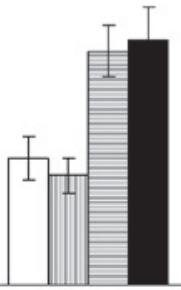

p-JNK1/JNK

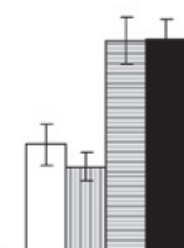

$\square$ Curcumin -/ATB-737 -

$\square$ Curcumin +/ABT-373 -

$\square$ Curcumin -/ABT-737+

- Curcum in +/ABT-737+

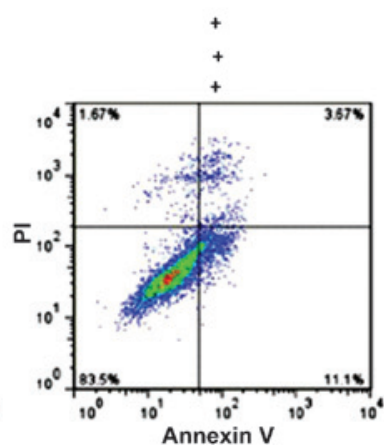

C

D
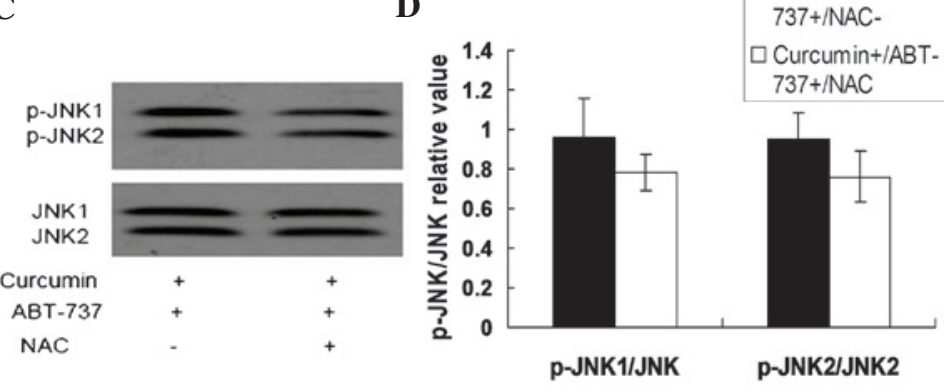

Figure 4. Increased levels of ROS promote the sustained activation of JNK, which leads to the apoptosis of HepG2 cells. (A) HepG2 cells were separately treated with $1 \%$ dimethyl sulfoxide, $2 \mu \mathrm{M}$ curcumin, $10 \mu \mathrm{M}$ ABT-737 and $2 \mu \mathrm{M}$ curcumin+10 $\mu \mathrm{M}$ ABT-737 for $24 \mathrm{~h}$, following which the total cellular proteins were extracted. Subsequently, the protein levels of p-JNK1/JNK2 and total JNK1/JNK2 were detected using western blotting. (B) HepG2 cells were treated with $2 \mu \mathrm{M}$ curcumin $+10 \mu \mathrm{M} \mathrm{ABT-737}$ for $24 \mathrm{~h}$ in the presence or absence of $10 \mu \mathrm{M}$ SP600125 (a JNK inhibitor). Following treatment, apoptosis of the HepG2 cells was assessed using annexin V-fluorescein isothiocyanate/PI staining. (C) HepG2 cells were treated with $2 \mu \mathrm{M}$ curcumin $+10 \mu \mathrm{M}$ ABT-737 for $24 \mathrm{~h}$ in the presence or absence of antioxidant, NAC $(10 \mathrm{mM})$. Subsequently, the levels of p-JNK1/JNK2 and total JNK1/JNK2 were detected using western blotting. (D) HepG2 cells were separately transfected with control siRNA or ASK1 siRNA for $24 \mathrm{~h}$, following which the cells were treated with $2 \mu \mathrm{M}$ curcumin+10 $\mu \mathrm{M}$ ABT-737 for $24 \mathrm{~h}$. A Trypan blue exclusion assay was then used to measure the total cell death ratio. "P<0.05 vs. control. ROS, reactive oxygen species; JNK, c-Jun N-terminal kinase; p-, phosphorylated; siRNA, small interfering RNA; PI, propidium iodide. 
curcumin may enhance the cytotoxicity of ABT-737 via the sustained activation of JNK. Additionally, the antioxidant, NAC, was able to reverse the activation of JNK induced by the co-treatment of curcumin and ABT-737 (Fig. 4C), which suggested that the increased ROS levels in the curcumin and ABT-737 co-treated cells activated JNK. Downregulating the level of ASK1, which is often important in the ROS-mediated activation of JNK (16), by siRNA attenuated the synergistic cytotoxicity of curcumin and ABT-737 on the HepG2 cells (Fig. 4D). These data indicated that curcumin enhanced the antitumor effect of ATB-737, which was partially dependent on the ROS-ASK1-JNK pathway.

\section{Discussion}

The pathology of HCC is complex, which presents a challenge in the development of effective treatments for $\operatorname{HCC}(37,38)$. Certain novel strategies of combination therapy have been investigated previously, and have shown potent antitumor activity in pre-clinical tests (39-44). Combination therapy appears to be is a promising strategy for patients with $\mathrm{HCC}$, due to the fact that it can improve the treatment effect and also alleviate the side effects of the drugs (40). Previous studies have confirmed that curcumin and ABT-737 are potential anticancer drugs, and can induce cell death in HCC cells in a dose-dependent manner $(13,45,46)$. In the present study, it was found that $2 \mu \mathrm{M}$ curcumin alone had no significant cytotoxic effects on the HepG2 cells, however it enhanced the antitumor effect of ABT-737 on HepG2 cells. The results indicated that curcumin markedly enhanced the level of ROS in ABT-737-treated cells. In addition, the increased ROS levels resulted in the promotion of HepG2 cell apoptosis, which was partially dependent on the ASK1-mediated sustained activation of JNK. Therefore, the combination of curcumin and ABT-737 may serve as a potential therapeutic treatment strategy for patients with HCC.

ROS are important in regulating cell survival and cell death (47). It has been reported that low levels of ROS promote cell survival via multiple signaling pathways, whereas high levels of ROS can be ab important mechanism of cell death (47). A previous study confirmed that ABT-737 resulted in low levels of ROS in HepG2 cells, which may have promoted cell survival via cytoprotective autophagy (16). In the present study, curcumin significantly increased the levels of ROS in the ABT-737-treated HepG2 cells. Notably, the increased levels of ROS did not further promote cell survival, however, it markedly induced cell death. The different levels of ROS may have determined the pro-survival or pro-apoptotic roles in HCC cells. In addition, the reason for the marked increase in the levels of ROS may be associated with mitochondrial stress-induced damage following administration of the combination of the two drugs. The associated mechanisms require further investigation.

JNK is a member of the mitogen-activated protein kinase family and has three isoforms, including JNK1, JNK2 and JNK3 (48). JNK can be activated through the phosphorylation of the Thr residue under diverse types of stress, including ROS $(35,49,50)$. JNK is involved in the regulation of various cellular process, including proliferation, differentiation, cell death and survival (51). In addition, the activation of JNK is closely associated with the carcinogenesis, development and treatment of HCC (52). Previous studies have demonstrated that ABT-737-mediated activation of JNK can either promote cell survival or lead to cell death in different types of HCC cell $(13,16,17)$. In the present study, it was found that JNK was not activated at the $18 \mathrm{~h}$ time point in HepG2 cells with ABT-737 treatment alone, however, it was activated when the cells were co-treated with curcumin and ABT-737. In addition, the activation of JNK significantly promoted cell death, which suggested the pro-apoptotic role of JNK under these conditions. The downregulation of ASK1, a key mediator of the ROS-JNK pathway (53), was observed to markedly reduce the total cell death rate in the curcumin and ABT-737 co-treated cells. However, the downstream signaling pathways of activated JNK in the HepG2 cells with the co-treatment of curcumin and ABT-737 are complex, therefore, the detailed mechanisms require further investigation.

Collectively, the present study indicated that the combination of curcumin and ABT-737 can efficaciously induce the death of HCC cells, and may offer a potential treatment strategy for patients with HCC.

\section{References}

1. El-Serag HB and Rudolph KL: Hepatocellular carcinoma: Epidemiology and molecular carcinogenesis. Gastroenterology 132: 2557-2576, 2007.

2. Llovet JM: Updated treatment approach to hepatocellular carcinoma. J Gastroenterol 40: 225-235, 2005.

3. Peck-Radosavljevic M: Drug therapy for advanced-stage liver cancer. Liver Cancer 3: 125-131, 2014.

4. Levine B, Sinha S and Kroemer G: Bcl-2 family members: Dual regulators of apoptosis and autophagy. Autophagy 4: 600-606, 2008.

5. Czabotar PE, Lessene G, Strasser A and Adams JM: Control of apoptosis by the BCL-2 protein family: Implications for physiology and therapy. Nat Rev Mol Cell Biol 15: 49-63, 2014.

6. Su J, Zhou L, Xia MH, Xu Y, Xiang XY and Sun LK: Bcl-2 family proteins are involved in the signal crosstalk between endoplasmic reticulum stress and mitochondrial dysfunction in tumor chemotherapy resistance. Biomed Res Int 2014: 234370, 2014.

7. Guo XZ, Shao XD, Liu MP, Xu JH, Ren LN, Zhao JJ, Li HY and Wang D: Effect of bax, bcl-2 and bcl-xL on regulating apoptosis in tissues of normal liver and hepatocellular carcinoma. World J Gastroenterol 8: 1059-1062, 2002.

8. Chun E and Lee KY: Bcl-2 and Bcl-xL are important for the induction of paclitaxel resistance in human hepatocellular carcinoma cells. Biochem Biophys Res Commun 315: 771-779, 2004.

9. Schattenberg JM, Schuchmann M and Galle PR: Cell death and hepatocarcinogenesis: Dysregulation of apoptosis signaling pathways. J Gastroenterol Hepatol 26 (Suppl 1): 213-219, 2011.

10. Balakrishnan K and Gandhi V: Bcl-2 antagonists: A proof of concept for CLL therapy. Invest New Drugs 31: 1384-1394, 2013.

11. Billard C: BH3 mimetics: Status of the field and new developments. Mol Cancer Ther 12: 1691-1700, 2013.

12. Yu L and Liu S: Autophagy contributes to modulating the cytotoxicities of Bcl-2 homology domain-3 mimetics. Semin Cancer Biol 23: 553-560, 2013.

13. Hikita H, Takehara T, Shimizu S, Kodama T, Shigekawa M, Iwase K, Hosui A, Miyagi T, Tatsumi T and Ishida H: The Bcl-xL inhibitor, ABT-737, efficiently induces apoptosis and suppresses growth of hepatoma cells in combination with sorafenib. Hepatology 52: 1310-1321, 2010.

14. Wang $\mathrm{G}$, Zhan $\mathrm{Y}$, Wang $\mathrm{H}$ and $\mathrm{Li} \mathrm{W}$ : ABT-263 sensitizes TRAIL-resistant hepatocarcinoma cells by downregulating the Bcl-2 family of anti-apoptotic protein. Cancer Chemother Pharmacol 69: 799-805, 2012.

15. Zhang S, Li G, Ma X, Wang Y, Liu G, Feng L, Zhao Y, Zhang G, Wu Y and Ye X: Norcantharidin enhances ABT-737-induced apoptosis in hepatocellular carcinoma cells by transcriptional repression of Mcl-1. Cell Signal 24: 1803-1809, 2012. 
16. Ni Z, Wang B, Dai X, Ding W, Yang T, Li X, Lewin S, Xu L, Lian $J$ and He F: HCC cells with high levels of Bcl-2 are resistant to ABT-737 via activation of the ROS-JNK-autophagy pathway. Free Radic Biol Med 70: 194-203, 2014.

17. Wang B, Ni Z, Dai X, Qin L, Li X, Xu L, Lian J and He F: The $\mathrm{Bcl}-2 / \mathrm{xL}$ inhibitor ABT-263 increases the stability of Mcl-1 mRNA and protein in hepatocellular carcinoma cells. Mol Cancer 13: 98, 2014.

18. Shehzad A, Lee J and Lee YS: Curcumin in various cancers. Biofactors 39: 56-68, 2013.

19. Witkin JM and Li X: Curcumin, an active constiuent of the ancient medicinal herb Curcuma longa L: Some uses and the establishment and biological basis of medical efficacy. CNS Neurol Disord Drug Targets 12: 487-497, 2013.

20. Li Y and Zhang T: Targeting cancer stem cells by curcumin and clinical applications. Cancer Lett 346: 197-205, 2014.

21. Prasad S, Gupta SC, Tyagi AK and Aggarwal BB: Curcumin a component of golden spice: From bedside to bench and back. Biotechnol Adv 32: 1053-1064, 2014.

22. Chuang SE, Kuo ML, Hsu CH, Chen CR, Lin JK, Lai GM, Hsieh CY and Cheng AL: Curcumin-containing diet inhibits diethylnitrosamine-induced murine hepatocarcinogenesis Carcinogenesis 21: 331-335, 2000.

23. Liu H, Liang Y, Wang L, Tian L, Song R, Han T, Pan S and Liu L: In vivo and in vitro suppression of hepatocellular carcinoma by EF24, a curcumin analog. PLoS One 7: e48075, 2012.

24. Xu MX, Zhao L, Deng C, Yang L, Wang Y, Guo T, Li L, Lin J and Zhang L: Curcumin suppresses proliferation and induces apoptosis of human hepatocellular carcinoma cells via the wnt signaling pathway. Int J Oncol 43: 1951-1959, 2013.

25. Zhang K, Rui X and Yan X: Curcumin inhibits the proliferation and invasiveness of MHCC $97-\mathrm{H}$ cells via p38 signaling pathway. Drug Dev Res 75: 463-468, 2014.

26. Yin H, Guo R, Xu Y, Zheng Y, Hou Z, Dai X, Zhang Z, Zheng D and $\mathrm{Xu} \mathrm{H}$ : Synergistic antitumor efficiency of docetaxel and curcumin against lung cancer. Acta Biochim Biophys Sin (Shanghai) 44: 147-153, 2012

27. Boztas AO, Karakuzu O, Galante G, Ugur Z, Kocabas F, Altuntas CZ and Yazaydin AO: Synergistic interaction of paclitaxel and curcumin with cyclodextrin polymer complexation in human cancer cells. Mol Pharm 10: 2676-2683, 2013.

28. Debata PR, Begum S, Mata A, Genzer O, Kleiner MJ, Banerjee $\mathrm{P}$ and Castellanos MR: Curcumin potentiates the ability of sunitinib to eliminate the VHL-lacking renal cancer cells 786-O: Rapid inhibition of Rb phosphorylation as a preamble to cyclin D1 inhibition. Anticancer Agents Med Chem 13: 1508-1513, 2013.

29. Guo J, Li W, Shi H, Xie X, Li L, Tang H, Wu M, Kong Y, Yang L and Gao J: Synergistic effects of curcumin with emodin against the proliferation and invasion of breast cancer cells through upregulation of miR-34a. Mol Cell Biochem 382: 103-111, 2013

30. Meiyanto E, Putri DD, Susidarti RA, Murwanti R, Sardjiman, Fitriasari A, Husnaa U, Purnomo $\mathrm{H}$ and Kawaichi M: Curcumin and its analogues (PGV-0 and PGV-1) enhance sensitivity of resistant MCF-7 cells to doxorubicin through inhibition of HER2 and NF-kB activation. Asian Pac J Cancer Prev 15: 179-184, 2014.

31. Ranjan K, Sharma A, Surolia A and Pathak C: Regulation of HA14-1 mediated oxidative stress, toxic response and autophagy by curcumin to enhance apoptotic activity in human embryonic kidney cells. Biofactors 40: 157-169, 2014.

32. Zhou QM, Chen QL, Du J, Wang XF, Lu YY, Zhang H and Su SB Synergistic effect of combinatorial treatment with curcumin and mitomycin $\mathrm{C}$ on the induction of apoptosis of breast cancer cells: A cDNA microarray analysis. Int J Mol Sci 15: 16284-16301, 2014.

33. Konopleva M, Contractor R, Tsao T, Samudio I, Ruvolo PP, Kitada S, Deng X, Zhai D, Shi YX, Sneed T, et al: Mechanisms of apoptosis sensitivity and resistance to the BH3 mimetic ABT-737 in acute myeloid leukemia. Cancer Cell 10: 375-388, 2006.
34. Kline MP, Rajkumar SV, Timm MM, Kimlinger TK, Haug JL, Lust JA, Greipp PR and Kumar S: ABT-737, an inhibitor of Bcl-2 family proteins, is a potent inducer of apoptosis in multiple myeloma cells. Leukemia 21: 1549-1560, 2007.

35. Biswas N, Mahato SK, Chowdhury AA, Chaudhuri J, Manna A, Vinayagam J, Chatterjee S, Jaisankar P, Chaudhuri U and Bandyopadhyay S: ICB3E induces iNOS expression by ROS-dependent JNK and ERK activation for apoptosis of leukemic cells. Apoptosis 17: 612-626, 2012.

36. Shi Y, Nikulenkov F, Zawacka-Pankau J, Li H, Gabdoulline R, $\mathrm{Xu}$ J, Eriksson S, Hedström E, Issaeva N, Kel A, et al: ROS-dependent activation of JNK converts p53 into an efficient inhibitor of oncogenes leading to robust apoptosis. Cell Death Differ 21: 612-623, 2014.

37. Kalinski T and Roessner A: Hepatocellular carcinoma: Pathology and liver biopsy. Dig Dis 27: 102-108, 2009.

38. Effendi K and Sakamoto M: Molecular pathology in early hepatocarcinogenesis. Oncology 78: 157-160, 2010.

39. Ibrahim N, Yu Y, Walsh WR and Yang JL: Molecular targeted therapies for cancer: Sorafenib mono-therapy and its combination with other therapies (review). Oncol Rep 27: 1303-1311, 2012.

40. Lachenmayer A, Toffanin S, Cabellos L, Alsinet C, Hoshida Y, Villanueva A, Minguez B, Tsai HW, Ward SC, Thung S, et al: Combination therapy for hepatocellular carcinoma: Additive preclinical efficacy of the HDAC inhibitor panobinostat with sorafenib. J Hepatol 56: 1343-1350, 2012.

41. He S, Wei YZ, Wang GL, Xu YY, Zhou JM, Zhang YX and Chen L: Study of RNA interference targeting NET-1 combination with sorafenib for hepatocellular carcinoma therapy in vitro and in vivo. Gastroenterol Res Pract 2013: 685150, 2013.

42. Geng J, Li X, Lang X, Qiao C, Hu M, Yang J, Feng J and Lv M: Combination of cetuximab and rapamycin enhances the therapeutic efficacy in hepatocellular carcinoma. Technol Cancer Res Treat 13: 377-385, 2014.

43. Nasr M, Selima E, Hamed O and Kazem A: Targeting different angiogenic pathways with combination of curcumin, leflunomide and perindopril inhibits diethylnitrosamine-induced hepatocellular carcinoma in mice. Eur J Pharmacol 723: 267-275, 2014.

44. Wang F, Dai W, Wang Y, Shen M, Chen K, Cheng P, Zhang Y, Wang $\mathrm{C}, \mathrm{Li} \mathrm{J}$, Zheng Y, et al: The synergistic in vitro and in vivo antitumor effect of combination therapy with salinomycin and 5-fluorouracil against hepatocellular carcinoma. PLoS One 9: e97414, 2014

45. Darvesh AS, Aggarwal BB and Bishayee A: Curcumin and liver cancer: A review. Curr Pharm Biotechnol 13: 218-228, 2012.

46. Wang WH, Chiang IT, Ding K, Chung JG, Lin WJ, Lin SS and Hwang JJ: Curcumin-induced apoptosis in human hepatocellular carcinoma j5 cells: Critical role of $\mathrm{Ca}(+2)$-dependent pathway. Evid Based Complement Alternat Med 2012: 512907, 2012.

47. Navarro-Yepes J, Burns M, Anandhan A, Khalimonchuk O, del Razo LM, Quintanilla-Vega B, Pappa A, Panayiotidis MI and Franco R: Oxidative stress, redox signaling and autophagy: Cell death versus survival. Antioxid Redox Signal 21: 66-85, 2014.

48. Sehgal V and Ram PT: Network motifs in JNK signaling. Genes Cancer 4: 409-413, 2013.

49. Deng YT, Huang HC and Lin JK: Rotenone induces apoptosis in MCF-7 human breast cancer cell-mediated ROS through JNK and p38 signaling. Mol Carcinog 49: 141-151, 2010.

50. Bubici $C$ and Papa S: JNK signalling in cancer: In need of new, smarter therapeutic targets. Br J Pharmacol 171: 24-37, 2014.

51. Seki E, Brenner DA and Karin M: A liver full of JNK: Signaling in regulation of cell function and disease pathogenesis and clinical approaches. Gastroenterology 143: 307-320, 2012.

52. Yan F, Wang XM, Liu ZC, Pan C, Yuan SB and Ma QM: JNK1, JNK2 and JNK3 are involved in P-glycoprotein-mediated multidrug resistance of hepatocellular carcinoma cells. Hepatobiliary Pancreat Dis Int 9: 287-295, 2010.

53. Hayakawa R, Hayakawa T, Takeda $\mathrm{K}$ and Ichijo $\mathrm{H}$ : Therapeutic targets in the ASK1-dependent stress signaling pathways. Proc Jpn Acad Ser B Phys Biol Sci 88: 434-453, 2012. 